\title{
ASO Visual Abstract: Impact of Residential Racial Integration on Postoperative Outcomes Among Medicare Beneficiaries Undergoing Resection for Cancer
}

\author{
Alessandro Paro, MD, Djhenne Dalmacy, MS, J. Madison Hyer, MS, Diamantis I. Tsilimigras, MD, \\ Adrian Diaz, MD, and Timothy M. Pawlik, MD, MPH, MTS, PhD \\ Department of Surgery, Wexner Medical Center and James Cancer Hospital and Solove Research Institute, The Urban \\ Meyer III and Shelley Meyer Chair for Cancer Research, The Ohio State University, Columbus, OH
}

The impact of residential segregation on surgical outcomes remains poorly defined. Data in the current study (https://doi.org/10.1245/s10434-021-10034-w) demonstrated that patients who resided in counties with a lower integration index were less likely to have an optimal textbook outcome following resection of cancer compared with patients who resided in more integrated counties. Increased residential racial diversity and integration may be important drivers to improve patient outcomes.

DISCLOSURE The authors declare that they have no Conflicts of interest.

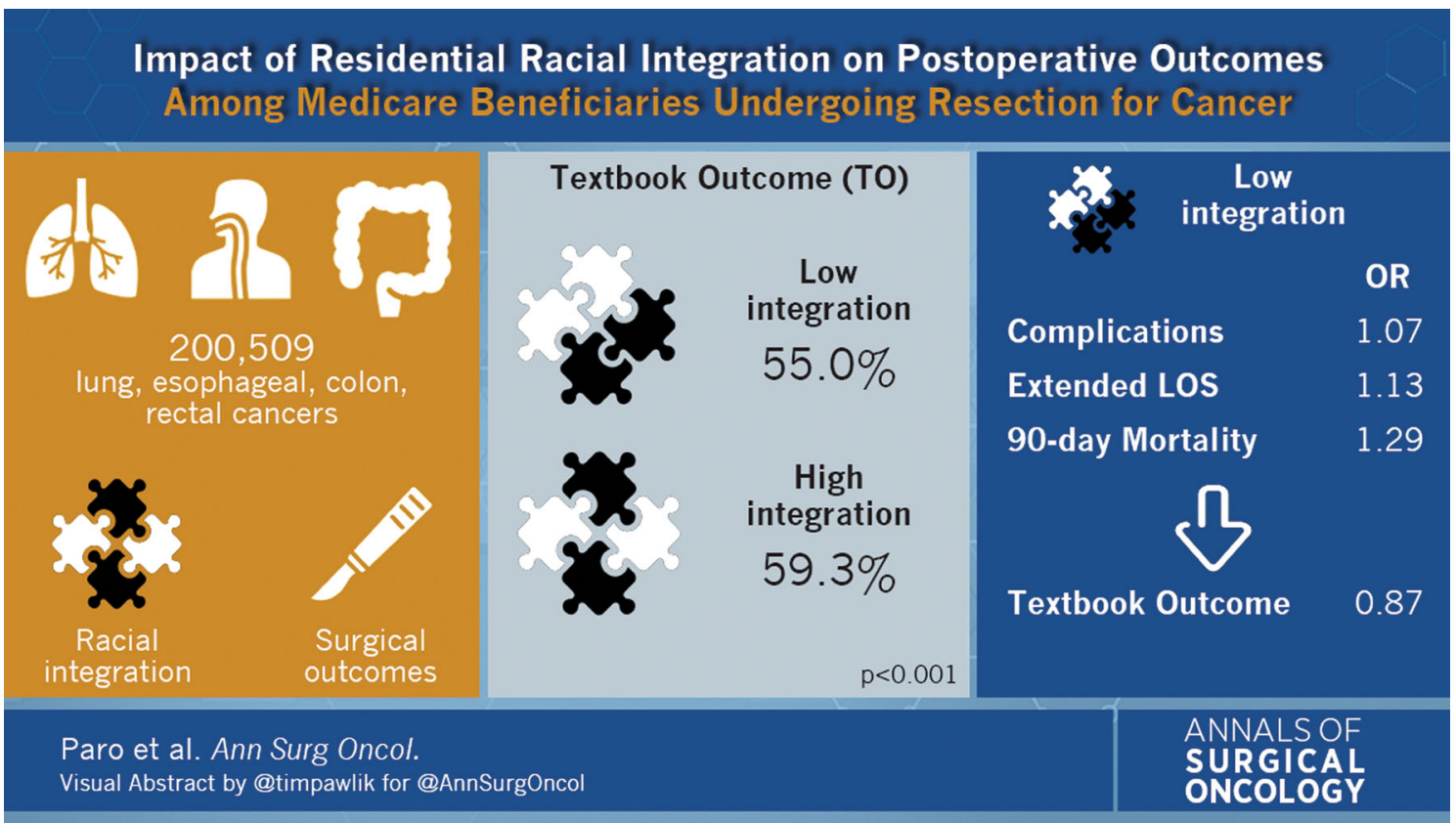

(C) Society of Surgical Oncology 2021

Published Online: 26 April 2021

T. M. Pawlik, MD, MPH, MTS, PhD

e-mail: tim.pawlik@osumc.edu

Publisher's Note Springer Nature remains neutral with regard to jurisdictional claims in published maps and institutional affiliations. 